\title{
The impact of COVID-19 pandemic on orthopaedic resident education: a nationwide survey study in South Korea
}

\author{
Dong-Gune Chang ${ }^{1}$ (D) Jong-Beom Park ${ }^{2}$ (D) - Goo Hyun Baek ${ }^{3}$ (D) Hong Jin Kim ${ }^{1}$ (D) $\cdot$ Aju Bosco ${ }^{4}$ (D) \\ Hwee Weng Dennis Hey ${ }^{5}$ (D) Choon-Ki Lee ${ }^{3}$ (D)
}

Received: 12 June 2020 / Accepted: 6 July 2020 / Published online: 10 July 2020

(C) SICOT aisbl 2020

\begin{abstract}
Purpose There have not been well-designed survey studies investigating the impact of the coronavirus disease 2019 (COVID-19) pandemic on orthopaedic resident education.

Methods A 58-question, web-based survey was administered to orthopaedic residents in South Korea. A total of 229 orthopaedic residents from 43 hospitals completed the survey questionnaire.

Results The average working time of 72.7 hours/week before the pandemic was decreased to 65.6 hours/week during the pandemic $(p<0.001)$. The time working in the operating room was significantly decreased during the pandemic, but not in the emergency centre and outpatient clinic. The education times for lecture and clinical case discussion were decreased during the pandemic (both, $p<0.001$ ), respectively. While the use of traditional teaching methods was decreased, the use of online-based teaching methods was increased $(p<0.001)$. However, satisfaction level with online-based teaching methods was significantly lower compared with that of traditional teaching methods. The average working time exposed to the patients with COVID-19 was 9.7 hours/week. About $47.6 \%$ of orthopaedic residents experienced isolation or quarantine. The average score for quality of life, which was 68.9 out of 100 scores before the pandemic, decreased to 61.7 during the pandemic $(p<0.001)$. The most stressful factor for orthopaedic residents during the pandemic was family/relative health, followed by their own health and residency program.

Conclusion The COVID-19 pandemic had a significant impact on orthopaedic resident education in South Korea. Therefore, flexible and sustainable strategies are necessary to prepare for the future as well as the current pandemic situation.
\end{abstract}

Keywords COVID-19 $\cdot$ Orthopaedic $\cdot$ Resident $\cdot$ Education $\cdot$ Impact

\section{Introduction}

The coronavirus disease 2019 (COVID-19), caused by severe acute respiratory syndrome coronavirus 2 (SARS-CoV-2) or

IRB status: This nationwide survey study was approved by the Institutional Review Board of the Uijeongbu St. Mary's Hospital (IRB number: UC20QADI0086), College of Medicine, The Catholic University of Korea, and an informed written consent was waived from the participants for the survey study and publication of this study.

Jong-Beom Park spinepjb@catholic.ac.kr

1 Department of Orthopaedic Surgery, Inje University Sanggye Paik Hospital, College of Medicine, Inje University, Seoul, South Korea

2 Department of Orthopaedic Surgery, Uijeongbu St. Mary's Hospital, College of Medicine, The Catholic University of Korea, Korea. 271 Cheonbo-ro, Uijeongbu-si, Gyeonggi-do 11765, South Korea human coronavirus 2019 (HCoV-19), was first detected in Wuhan, China, in November 2019 [1]. Its potential to generate explosive outbreaks in confined settings and cross borders following human mobility patterns has already been reported
3 Department of Orthopaedic Surgery, Seoul National University College of Medicine, Seoul National University Hospital, Seoul, South Korea

4 Orthopedic Spine Surgery Unit, Institute of Orthopedics and Traumatology, Madras Medical College, Chennai, India

5 University Spine Centre, Department of Orthopaedic Surgery, National University Hospital, National University Health System, Singapore, Singapore 
[1-6]. Since the first COVID-19 patient was found in South Korea on January 19, 2020, COVID-19 has spread nationwide rapidly. In order to cope with this pandemic situation, the Korean government raised the crisis alert level to the highest and reacted actively and quickly. The Korean Society of Laboratory Medicine set up and operated rapid, large-scale laboratories for COVID-19 screening testing in 638 hospitals throughout South Korea. At the same time, the Korean government has conducted aggressive contact tracing and quarantine of contacted people with confirmed active COVID-19 patients to prevent the spread of it. As of May 2, 2020, the same time as the survey, the total numbers of confirmed and deceased COVID-19 patients were 10,780 and 250, respectively $[2,3]$.

There have been many discussions about the issues that confront orthopaedic residents in the COVID-19 pandemic situation [7-9]. Redefined concepts of education for orthopaedic residents have been reported owing to the rapidly evolving crisis [10]. Particularly, with respect to education during the COVID-19 pandemic, a great deal of flexibility and a sustainable system delivered by providers and accepted by learners as well as novel institutional education methods are essential for orthopaedic residents [11]. However, there have not been well-designed survey studies investigating the impact of the COVID-19 pandemic on orthopaedic resident education. Therefore, this nationwide survey study aimed to investigate the impact of the COVID-19 pandemic on orthopaedic resident education in South Korea.

\section{Materials and methods}

\section{Study design and survey responders}

A 58-question, web-based survey was conducted to orthopaedic residents through our research group from April 27 to May 2, 2020, by web link or e-mail invitation. The questions were divided into six subgroups:

(1) General demographics: orthopaedic residents were asked about their age, sex, housing, working place, and grade.

(2) Details of residency programs before the onset of COVID-19: average working time/week; number of hours spent/week in specific locations including an operation room, emergency centre, and outpatient clinic; number of hours/week participating in teaching programs; and institutional methods for education before the COVID-19 pandemic.

(3) Assessment of training level in handling the COVID-19 pandemic: experiences with previous outbreaks, level of expertise, and valid training with certifications.

(4) Changes in residency program: most questions were similar to subgroup 2 except that this was during the
COVID-19 pandemic. We considered further questions about the working hours/week and specific locations of exposure to patients with COVID-19, the level of providing personal protective equipment (PPE), and the experiences of dispatch, isolation, or quarantine for orthopaedic residents.

(5) Mental health assessment of orthopaedic residents: the level of worry, the degree of social acceptance, and stress during the COVID-19 pandemic.

(6) Institution preparedness assessment: PPE availability and whether or not there were formal guidelines to tackle such outbreaks in institutions.

The survey questionnaire was developed by two study coauthors ( $\mathrm{AB}$ and $\mathrm{HWDH})$. The study was approved by the Institutional Review Board (IRB number: UC20QADI0086).The primary goal was to collect data on orthopaedic resident education during the COVID-19 pandemic and the secondary goal was to investigate the impact of COVID-19 on orthopaedic resident education in South Korea.

\section{Data collection and statistical analysis}

Data were initially elaborated using Google online survey platforms. We calculated that a sample size of 229 orthopaedic residents would provide and detect mean values using a twosided significance level of 0.05 . Working and education hours, satisfaction level with education methods, and participant quality of life were compared using mean difference on 95\% confidence intervals, and Student's $t$ test (paired two sample for means) was used for statistical analysis. Detailed working and education patterns were assessed by CochranArmitage test for trend. Institutional methods of education were compared using the chi-square test of independence. Stressful factors for subjects were compared using one-way analysis of variance (ANOVA) and post hoc analysis using the Scheffe test. Statistical analyses were performed with the use of SAS software, version 9.4 (SAS Institute). $P<0.05$ was considered statistically significant.

\section{Results}

\section{Demographic data}

A total of 229 orthopaedic residents from 43 hospitals in South Korea completed an online survey questionnaire. The participant demographic data are presented in Table 1. The mean age was 30.7 years (range, 25-39); 219 residents were male, seven were female, and three were not answered. Most orthopaedic residents lived alone (university resident quarters, $32.8 \%$; alone in residence, $31.4 \%$ ) or with their family 
Table 1 Demographic data of orthopaedic residents responding to survey questionnaire

\begin{tabular}{|c|c|c|}
\hline Variables & $\begin{array}{l}\text { No. of residents } \\
(N=229)\end{array}$ & $\begin{array}{l}\text { Percentage } \\
(\%)\end{array}$ \\
\hline \multicolumn{3}{|l|}{ Age (year) } \\
\hline $25-29$ & 81 & 35.4 \\
\hline $30-34$ & 109 & 47.6 \\
\hline $35-39$ & 28 & 12.2 \\
\hline Not answered & 11 & 4.8 \\
\hline \multicolumn{3}{|l|}{ Sex } \\
\hline Male & 219 & 95.6 \\
\hline Female & 7 & 3.1 \\
\hline Not answered & 3 & 1.3 \\
\hline \multicolumn{3}{|l|}{ Housing } \\
\hline In university resident quarters & 75 & 32.8 \\
\hline Alone in residence & 72 & 31.4 \\
\hline With friends or colleagues & 14 & 6.1 \\
\hline With own family & 57 & 24.9 \\
\hline With own extended family & 7 & 3.1 \\
\hline Not answered & 4 & 1.7 \\
\hline \multicolumn{3}{|l|}{ Working place } \\
\hline Private non-university hospital & 8 & 3.5 \\
\hline $\begin{array}{l}\text { Private university-affiliated } \\
\text { hospital/college }\end{array}$ & 118 & 51.5 \\
\hline Public non-university hospital & 10 & 4.4 \\
\hline $\begin{array}{l}\text { Public university-affiliated } \\
\text { hospital/college }\end{array}$ & 86 & 37.6 \\
\hline Not answered & 7 & 3.0 \\
\hline \multicolumn{3}{|l|}{ Residents' grades } \\
\hline 1 & 54 & 23.6 \\
\hline 2 & 60 & 26.2 \\
\hline 3 & 48 & 21.0 \\
\hline 4 & 59 & 25.8 \\
\hline Not answered & 8 & 3.4 \\
\hline
\end{tabular}

$N$ number of responders

(24.9\%) except for not answered orthopaedic residents $(1.7 \%)$. According to the structural characteristics of hospitals in South Korea, $51.5 \%$ of them were working at a private university-affiliated hospital/college, $37.6 \%$ at a public university-affiliated hospital/college, and $7.9 \%$ at training hospitals other than university-affiliated hospitals. Three percent were not answered. The grades of orthopaedic residents were normally distributed (grade 1, 23.6\%; grade 2, 26.2\%; grade 3,21.0\%; grade 4, 25.8\%; not answer, $3.4 \%$ ).

\section{Working time of orthopaedic residents}

The average working time for orthopaedic residents was 72.7 hours/week (95\% confidence interval (CI), 70.6 to 74.8) before the COVID-19 pandemic and 65.6 hours/week (95\% CI, 61.0 to 70.2 ) during the COVID-19 pandemic, which was significantly different $(p<0.001,[95 \%$ CI, mean difference 3.57 (3.20-11.09)]) (Table 2). Working time in the operating room was significantly decreased during the COVID-19 pandemic $(p<0.001)$. The majority $(68.1 \%)$ of orthopaedic residents participated in surgeries for more than ten hours/week before the COVID-19 pandemic, but about half $(47.6 \%)$ participated in surgeries for more than ten hours/week during the COVID-19 pandemic. The difference was statistically significant $(p<0.001)$. However, changes in working time in the emergency centre and outpatient clinic were not statistically different before and during the COVID-19 pandemic. About 34.5\% of orthopaedic residents participated in the emergency centre for more than 25 hours/ week before the COVID-19 pandemic, but the percentages decreased to $25.8 \%$ of that time during the COVID-19 pandemic. However, this was not statistically different ( $p=$ 0.104 ). About $31.9 \%$ of orthopaedic residents participated in outpatient clinic practice for more than ten hours/week before the COVID-19 pandemic, but the percentages decreased to $25.8 \%$ of that time during the COVID-19 pandemic. However, this was not statistically different $(p=0.192)$.

\section{Education time for orthopaedic residents}

The education times for lecture and clinical case discussion were significantly decreased during the COVID-19 pandemic (Table 2). With respect to time for lectures, about $27.1 \%$ of orthopaedic residents attended more than six hours/week before the COVID-19 pandemic. However, only about $14.4 \%$ of orthopaedic residents attended more than six hours/week during the COVID-19 pandemic, which was statistically different $(p<0.001)$. With respect to time for clinical case discussion, about $19.7 \%$ of orthopaedic residents attended more than six hours/week before the COVID-19 pandemic. However, only about $9.6 \%$ of orthopaedic residents attended more than six hours/week during the COVID-19 pandemic, which was also statistically different $(p<0.001)$.

\section{Institutional methods of education for orthopaedic residents}

Institutional methods for education were significantly changed during the COVID-19 pandemic $(p<0.001)$ (Table 3). Traditional teaching methods including lecture delivery by faculty, clinical demonstration by faculty, journal club and other interactive classes, and symposium were significantly decreased during the COVID-19 pandemic. On the contrary, online-based teaching methods including webinar and online symposium, telecasting of recorded lectures, and telecasting recorded video of surgeries with discussion by faculty significantly increased during the COVID-19 pandemic. However, the average satisfaction level for online-based teaching methods ( 2.7 of 5 ) was significantly lower compared 
Table 2 Working and education times of orthopaedic residents

\begin{tabular}{|c|c|c|c|}
\hline Variables & $\begin{array}{l}\text { Before COVID-19 } \\
\text { pandemic }\end{array}$ & $\begin{array}{l}\text { During COVID-19 } \\
\text { pandemic }\end{array}$ & $\begin{array}{l}P \text { value } \\
\text { Mean difference } \\
(95 \% \mathrm{CI})\end{array}$ \\
\hline Working time & 72.7 & 65.6 & $<0.001^{*}$ \\
\hline (hours/week) & $(70.6-74.8)$ & $(61.0-70.2)$ & $3.57(3.20-11.09)^{* *}$ \\
\hline \multicolumn{4}{|l|}{ Detailed working time } \\
\hline Operation room (hours/week) - No. & & & $<0.001^{\dagger}$ \\
\hline $0-2$ & 11 & 26 & \\
\hline $3-5$ & 29 & 44 & \\
\hline $6-10$ & 27 & 43 & \\
\hline $11-15$ & 37 & 35 & \\
\hline $16-20$ & 30 & 22 & \\
\hline$>20$ & 89 & 52 & \\
\hline Not answered & 6 & 7 & \\
\hline Total & 229 & 229 & \\
\hline \multicolumn{3}{|l|}{ Emergency centre (hours/week)—No. } & $0.104^{\dagger}$ \\
\hline $0-6$ & 42 & 56 & \\
\hline $7-12$ & 47 & 50 & \\
\hline $13-24$ & 56 & 57 & \\
\hline $25-48$ & 49 & 35 & \\
\hline $49-72$ & 11 & 9 & \\
\hline$>72$ & 19 & 15 & \\
\hline Not answered & 5 & 7 & \\
\hline Total & 229 & 229 & \\
\hline \multicolumn{3}{|l|}{ Outpatient clinic (hours/week)—No. } & $0.192^{\dagger}$ \\
\hline $0-2$ & 42 & 43 & \\
\hline $3-5$ & 41 & 52 & \\
\hline $6-10$ & 66 & 68 & \\
\hline $11-15$ & 43 & 35 & \\
\hline$>15$ & 30 & 24 & \\
\hline Not answered & 7 & 7 & \\
\hline Total & 229 & 229 & \\
\hline \multicolumn{4}{|l|}{ Detailed education time } \\
\hline Lecture (hours/week)—No. & & & $<0.001^{\dagger}$ \\
\hline $0-2$ & 51 & 99 & \\
\hline $3-5$ & 110 & 88 & \\
\hline $6-10$ & 45 & 25 & \\
\hline$>10$ & 17 & 8 & \\
\hline Not answered & 6 & 9 & \\
\hline Total & 229 & 229 & \\
\hline $\begin{array}{l}\text { Clinical case discussion } \\
\text { (hours/week)—No. }\end{array}$ & & & $<0.001^{\dagger}$ \\
\hline $0-2$ & 70 & 135 & \\
\hline $3-5$ & 108 & 65 & \\
\hline $6-10$ & 45 & 22 & \\
\hline Not answered & 6 & 7 & \\
\hline Total & 229 & 229 & \\
\hline
\end{tabular}

${ }^{*} P$ value is calculated by paired $t$ test for working time

${ }^{* *}$ Mean difference for working time is expressed on $95 \%$ confidence level

${ }^{\dagger} P$ values are calculated by Cochran-Armitage trend test for detailed working and education times

COVID-19 coronavirus disease 2019, No. number of responders, $C I$ confidence interval with that of traditional teaching methods (3.4 of 5) $(p<0.001$, [95\% CI, mean difference $0.70(0.58-0.81)])$ (Table 3).

\section{Risk of COVID-19 exposure for orthopaedic residents}

The average time of exposure to both infected and suspected patients with COVID-19 in orthopaedic residents was about 9.7 hours/week from our survey. The main exposure locations were in the wards $(37.5 \%)$ and outpatient clinic (18.7\%)
(Table 4). The percentage of experience with isolation or quarantine was $47.6 \%$ (Table 4). The average satisfaction level of PPE was 3.3 of 5 and the average training percentage for donning and doffing of PPE was $53.3 \%$.

\section{Assessment of orthopaedic resident mental health}

The average score for quality of life was 68.9 of 100 scores (95\% CI, 68.8 to 69.0) before the COVID-19 pandemic and 
Table 3 Institutional methods of education used for orthopaedic residents

\begin{tabular}{llll}
\hline Variables & No. response of survey & & \multicolumn{1}{c}{$\begin{array}{c}\text { Satisfaction level } \\
\text { (Score) }\end{array}$} \\
\cline { 2 - 4 } & $\begin{array}{l}\text { Before COVID-19 } \\
\text { pandemic }\end{array}$ & $\begin{array}{l}\text { During COVID-19 } \\
\text { pandemic }\end{array}$ & $p<0.001^{\dagger}$ \\
\hline Institutional methods of education & & $p<0.001^{*}$ & $0.70(0.58-0.81)^{\dagger \dagger}$ \\
Traditional teaching methods & & $366(89.7 \%)$ & 3.4 \\
Lecture delivery by faculty & $394(95.6 \%)$ & $128(31.4 \%)$ & 3.6 \\
Clinical demonstration by faculty & $130(31.6 \%)$ & $119(29.2 \%)$ & 3.7 \\
Journal club-interactive classes & $114(27.7 \%)$ & $76(18.6 \%)$ & 3.1 \\
Symposium & $90(21.8 \%)$ & $43(10.5 \%)$ & 3.1 \\
Online-based teaching methods & $60(14.6 \%)$ & $42(10.3 \%)$ & 2.7 \\
Webinar and online symposium & $18(4.4 \%)$ & $23(5.6 \%)$ & 2.7 \\
Telecasting recorded lecture & $10(2.4 \%)$ & $10(2.5 \%)$ & 2.6 \\
Telecasting recorded video of surgeries & $3(0.7 \%)$ & $9(2.2 \%)$ & 2.7 \\
$\quad$ with discussion by faculty & $5(1.2 \%)$ & & \\
\hline
\end{tabular}

\$Satisfaction level is calculated by score 1 to 5 and measured mean value

${ }^{*} P$ value is calculated by chi-square test of independence between traditional and online-based teaching methods

${ }^{\dagger} P$ value is calculated by paired $t$ test for satisfaction level

${ }^{\dagger}$ Mean difference for satisfaction level is expressed on $95 \%$ confidence level

1 being not satisfied, 2 being least satisfied, 3 being satisfied, 4 being more than satisfied, 5 being well satisfied

No. number, COVID-19 coronavirus disease 2019

was decreased to 61.7 of 100 scores (95\% CI, 61.6 to 61.9 ) during the COVID-19 pandemic, which was statistically different $(p<0.001$, [95\% CI, mean difference $7.14(4.30-9.98)])$ (Table 5). The average score for stressful factors felt by orthopaedic residents during the COVID-19 pandemic was the highest for family/relative health, followed by their own health

Table 4 Risk of COVID-19 exposure on orthopaedic residents

\begin{tabular}{lll}
\hline Variables & $\begin{array}{l}\text { No. of } \\
\text { response }\end{array}$ & $\begin{array}{l}\text { Percentage } \\
(\%)\end{array}$ \\
\hline COVID-19 patient exposure & & \\
In ward & 94 & 37.5 \\
In the intensive care units (not on & 29 & 11.6 \\
$\quad$ ventilators) & 13 & 5.2 \\
With ventilator support & 47 & 18.7 \\
In outpatient clinic & 10 & 4.0 \\
Screening & 58 & 23.0 \\
Unspecified & & \\
Isolation or quarantine & 109 & 47.6 \\
Yes & 117 & 51.1 \\
No & 3 & 1.3 \\
Not answered & & \\
Donning and doffing of PPE as trained & 122 & 53.3 \\
Yes & 97 & 42.4 \\
No & 10 & 4.3 \\
Not answered &
\end{tabular}

COVID-19 coronavirus disease 2019

COVID-19 patients mean both infected and suspected patients

No., $N$ number, $P P E$ personal protective equipment and their residency program $(p<0.001)$ (Table 5$)$. In post hoc analysis, the comparisons between their own health and family/ relative health and family/relative health and residency program were significant (both, $p<0.001$ ), but their own health and residency program were not significant $(p=0.557)$.

\section{Discussion}

The COVID-19 pandemic has upended nearly every medical discipline and dramatically affected patient care and has had far-reaching effects on surgeon education [12-15]. In most countries of the world, elective orthopaedic surgery has mostly been cancelled or postponed to insure that resources are available for the critically ill and to minimize the spread of disease [16]. In addition, the majority of national and international orthopaedic conferences, training programs, and workshops have been postponed or cancelled. Therefore, there is a strong need to make a new delivery system for education to our colleagues, residents, and fellows [7, 8, 17-21].

Orthopaedic surgeons are considered non-essential healthcare providers during the COVID-19 pandemic [22, 23]. Many such residents have been redeployed. However, it is an unfamiliar territory for orthopaedic surgeons owing to lack of experience in intensive care unit (ICU) and respiratory care [9]. Moreover, there are unexpected, rapid, and comprehensive responses from the profession to reallocate its resources and to help the overall drive to reduce morbidity and mortality caused by the COVID-19 pandemic [17]. The 
Table 5 Assessment of mental health of orthopaedic residents

\begin{tabular}{llll}
\hline Variables & $\begin{array}{l}\text { Before COVID-19 } \\
\text { pandemic }\end{array}$ & $\begin{array}{l}\text { During COVID-19 } \\
\text { pandemic }\end{array}$ & $\begin{array}{l}P \text { value } \\
\text { Mean difference } \\
(95 \% \text { CI })\end{array}$ \\
\hline Quality of life $^{\$}$ & 68.9 & 61.7 & $<0.001^{*}$ \\
$($ Score 0-100) & $(68.8-69.0)$ & $(61.6-61.9)$ & $7.14(4.30-9.98)^{* *}$ \\
Stressful factors $\$$ & & & $<0.001^{\dagger}$ \\
$($ Score 0-5) & & 2.8 & \\
Their own health & 3.2 & \\
Family/relative health & & 2.6 & \\
Residency program & & & \\
\hline
\end{tabular}

$\$$ Quality of life is calculated by score 1 to 100 and measured mean value

${ }^{*} P$ value is calculated by paired $t$ test for quality of life

${ }^{* * *}$ Mean difference for quality of life is expressed on $95 \%$ confidence level

$\$ \$$ Stressful factors are calculated by score 1 to 5 and measured mean value on $95 \%$ confidence level

${ }^{\dagger} P$ values are calculated by one-way ANOVA test for stressful factors

$\$$ Post hoc analysis of different groups by Scheffe test on $95 \%$ confidence level

Their own health vs family/relative health: $p<0.001$

Family/relative health vs residency program: $p<0.001$

Their own health vs residency program: $p=0.557$

1 not worried at all, 2 least worried, 3 mild worried, 4 moderate worried, 5 most worried

COVID-19 coronavirus disease 2019, CI confidence interval
COVID-19 pandemic presents a challenge to orthopaedic resident education. Worldwide, elective surgeries are being deferred, and orthopaedic residents are asked to make drastic changes to their daily routines [10]. Therefore, this study aimed to investigate orthopaedic residents $(n=229)$ in terms of working hours, education, and mental health and demonstrated useful results about the actual impact of the COVID-19 pandemic on orthopaedic resident education in South Korea.

The total working hours for orthopaedic residents significantly decreased during the COVID-19 pandemic in South Korea, which was considered to have been due to several reasons, including cancellation of elective outpatient visits, significant decrease in the number of elective surgery, deployment to COVID-19 clinic, and isolation or quarantine [13]. Working time in the operating room was significantly decreased during the COVID-19 pandemic due to significant reduction in the number of elective surgery. A significant difference in the distribution of working time between elective and emergent surgery was considered due to the cancellation of a lot of elective orthopaedic surgery. This study did not show a significant change in time spent working in the emergency centre and outpatient clinic. Even though the number of patients visiting the outpatient clinic decreased to avoid COVID-19 infection, the actual working time at the emergency centre and outpatient clinic for orthopaedic residents was not less affected than expected [16]. This may be due to medical activities such as wearing PPE and preparing patients for treatment which require a lot of time.
Because of the COVID-19 pandemic, almost all academic meetings and conferences around the world have been cancelled or postponed, and this is the same in South Korea [16, $22,23]$. In addition, hospitals were ordered to minimize faceto-face education and conferences conducted by traditional teaching methods as much as possible. These regulations have made in-person orthopaedic resident education difficult and have reduced total education time. Accordingly, most departments of orthopaedic surgery began to conduct education and conferences using online-based teaching methods. Our results showed that the education times for lecture and clinical case discussion for orthopaedic residents significantly decreased in South Korea.

Institutional methods of education were significantly changed during the COVID-19 pandemic. While the use of traditional teaching methods was significantly decreased during the COVID-19 pandemic, the use of online-based teaching methods was significantly increased during the COVID-19 pandemic. However, the average satisfaction levels for onlinebased teaching methods were significantly lower than that of traditional teaching methods. Several studies have reported that virtual meetings and telecasting are considered to be more useful compared with conventional techniques such as staff lectures. These are also expected to be cost-effective even under normal circumstances [23]. Unlike other papers, our actual survey results showed that although online-based teaching methods increased during the COVID-19 pandemic, orthopaedic residents were not yet satisfied with these methods of education compared with traditional teaching methods. 
The social distancing measure was considered to be one of the most successful methods for preventing the spread of COVID-19 in South Korea [1-3]. The PPEs were adequately provided to orthopaedic residents who reported their degree of satisfaction with PPE provision was above average. Regarding the risk of COVID-19 exposure, there have been few reports that the main location for COVID-19 exposure was mostly in general wards. In our study, the main locations of risk for COVID-19 exposure in orthopaedic residents were the general wards, followed by the outpatient clinic and emergency centre. This result is consistent with the previous study [17]. Forty-eight percent of the orthopaedic residents' experience with isolation or quarantine was considered to be due to the aggressive contact tracing and active self-quarantine policy implemented by the Korean government to prevent the spread of COVID-19.

The quality of life of orthopaedic residents in South Korea is usually not high due to their heavy workload. In this study, the average score for quality of life was 68.9 of 100 score before the COVID-19 pandemic. However, the satisfaction level was significantly decreased to 61.7 of 100 scores during the COVID-19 pandemic. This result is thought to be closely related to the stressful factors felt by orthopaedic residents during the COVID-19 pandemic. Orthopaedic residents were most stressed by the possibility that they could spread the COVID-19 to their family/relatives rather than their own health and residency program. Therefore, hospitals and departments of orthopaedic surgery should pay more attention to the most serious stressors experienced by orthopaedic residents.

There are several limitations of this study. First, while data analysis using online survey questionnaires is considered useful and cost-effective during the COVID-19 pandemic, fundamental problems with the online survey itself cannot be completely excluded. Second, the number of orthopaedic residents in South Korea is 836, of which 229 responded to the survey for a response rate of $27.4 \%$.

\section{Conclusions}

In summary, the results of this nationwide survey study showed a significant impact of the COVID-19 pandemic on orthopaedic resident education program in South Korea. It is thought to be necessary to develop and expand non-contact education program during the COVID-19 pandemic period.

Acknowledgements We thank Sunghoon Choi, MS (Department of Statistics, Seoul National University), for the contribution of statistical analysis.

Funding information The authors indicated that there was no external funding for this study.

\section{Compliance with ethical standards}

Conflict of interest The authors declare that they have no conflict of interest.

Informed consent Informed consent was waived from all the participants included in the study.

Ethical approval This nationwide survey study was approved by the Institutional Review Board of the Uijeongbu St. Mary's Hospital (IRB number: UC20QADI0086), College of Medicine, The Catholic University of Korea, and an informed written consent was waived from the participants for the survey study and publication of this study.

\section{References}

1. Nishiura H, Jung SM, Linton NM, Kinoshita R, Yang Y, Hayashi K, Kobayashi T, Yuan B, Akhmetzhanov AR (2020) The extent of transmission of novel coronavirus in Wuhan, China, 2020. J Clin Med 9(2):330. https://doi.org/10.3390/jcm9020330

2. Kim JY, Choe PG, Oh Y, Oh KJ, Kim J, Park SJ, Park JH, Na HK, Oh (2020) The first case of 2019 novel coronavirus pneumonia imported into Korea from Wuhan, China: implication for infection prevention and control measures. J Korean Med Sci 35(5):e61. https://doi.org/10.3346/jkms.2020.35.e61

3. Korean Society of Infectious Diseases; Korean Society of Pediatric Infectious Diseases; Korean Society of Epidemiology; Korean Society for Antimicrobial Therapy; Korean Society for Healthcare-associated Infection Control and Prevention; Korea Centers for Disease Control and Prevention (2020) Report on the epidemiological features of coronavirus disease 2019 (COVID-19) outbreak in the Republic of Korea from January 19 to March 2, 2020. J Korean Med Sci 35(10):e112. https://doi.org/10.3346/jkms. 2020.35.e112

4. Jones DS (2020) History in a crisis - lessons for COVID-19. N Engl J Med 382(18):1681-1683. https://doi.org/10.1056/ NEJMp2004361

5. Zhang X (2020) Epidemiology of COVID-19. N Engl J Med 382(19):1869. https://doi.org/10.1056/NEJMc2005157

6. Arons MM, Hatfield KM, Reddy SC, Kimball A, James A, Jacobs JR, Taylor J, Spicer K, Bardossy AC, Oakley LP, Tanwar S, Dyal JW, Harney J, Chisty Z, Bell JM, Methner M, Paul P, Carlson CM, McLaughlin HP, Thornburg N, Tong S, Tamin A, Tao Y, Uehara A, Harcourt J, Clark S, Brostrom-Smith C, Page LC, Kay M, Lewis J, Montgomery P, Stone ND, Clark TA, Honein MA, Duchin JS, Jernigan JA, Public Health-Seattle and King County and CDC COVID-19 Investigation Team (2020) Presymptomatic SARSCoV-2 Infections and Transmission in a Skilled Nursing Facility. N Engl J Med 382(22):2081-2090. https://doi.org/10.1056/ NEJMoa2008457

7. Sarac NJ, Sarac BA, Schoenbrunner AR, Janis JE, Harrison RK, Phieffer LS, Quatman CE, Ly TV (2020) A review of state guidelines for elective orthopaedic procedures during the COVID-19 outbreak. J Bone Joint Surg Am 102(11):942-945. https://doi.org/ 10.2106/JBJS.20.00510

8. Rodrigues-Pinto R, Sousa R, Oliveira A (2020) Preparing to perform trauma and orthopaedic surgery on patients with COVID-19. J Bone Joint Surg Am 102(11):946-950. https://doi.org/10.2106/ JBJS.20.00454

9. Sarpong NO, Forrester LA, Levine WN (2020) What's important: redeployment of the orthopaedic surgeon during the COVID-19 pandemic: perspectives from the trenches. J Bone Joint Surg Am. https://doi.org/10.2106/JBJS.20.00574 
10. Kogan M, Klein SE, Hannon CP, Nolte MT (2020) Orthopaedic education during the COVID-19 pandemic. J Am Acad Orthop Surg 28(11):e456-e464. https://doi.org/10.5435/JAAOS-D-2000292

11. Chick RC, Clifton GT, Peace KM, Propper BW, Hale DF, Alseidi AA, Vreeland TJ (2020) Using technology to maintain the education of residents during the COVID-19 pandemic. J Surg Educ. https://doi.org/10.1016/j.jsurg.2020.03.018

12. Dowdell JE, Louie PK, Virk S, McCarthy MH, Sandhu HS, Qureshi SA, Albert TJ, Kim HJ (2020) Spine fellowship training reorganizing during a pandemic: perspectives from a tertiary orthopedic specialty center in the epicenter of outbreak. Spine J 26: S1529-9430(20)30165-0. https://doi.org/10.1016/j.spinee.2020. 04.015

13. Crosby DL, Sharma A (2020) Insights on otolaryngology residency training during the COVID-19 pandemic. Otolaryngol Head Neck Surg. https://doi.org/10.1177/0194599820922502

14. Zou J, Yu H, Song D, Niu J, Yang H (2020) Advice on standardized diagnosis and treatment for spinal diseases during the coronavirus disease 2019 pandemic. Asian Spine J. 14(2):258-263. https://doi. org/10.31616/asj.2020.0122

15. Sornsa-Ard T, Niramitsantiphong A, Liawrungrueang W (2020) Management of traumatic spinal fracture in the coronavirus disease 2019 situation. Asian Spine J. https://doi.org/10.31616/asj.2019. 0183

16. Haleem A, Javaid M, Vaishya R, Vaish A (2020) Effects of COVID-19 pandemic in the field of orthopaedics. J Clin Orthop Trauma 11(3):498-499. https://doi.org/10.1016/j.jcot.2020.03.015

17. Guo X, Wang J, Hu D, Wu L, Gu L, Wang Y, Zhao J, Zeng L, Zhang J, Wu Y (2020) Survey of COVID-19 disease among orthopaedic surgeons in Wuhan, People's Republic of China. J Bone
Joint Surg Am 102(10):847-854. https://doi.org/10.2106/JBJS.20. 00417

18. Meyer M, Prost S, Farah K, Denis JB, Dufour H, Blondel B, Fuentes $S$ (2020) Spine surgical procedures during coronavirus disease 2019 pandemic: is it still possible to take care of patients? Results of an observational study in the first month of confinement. Asian Spine J 14(3):336-340. https://doi.org/10.31616/asj.2020. 0197

19. Tan KA, Thadani VN, Chan D, Oh JY, Liu GK (2020) Addressing coronavirus disease 2019 in spine surgery: a rapid national consensus using the Delphi method via teleconference. Asian Spine J 14(3):373-381. https://doi.org/10.31616/asj.2020.0224

20. LaPorte DM, Tornetta P, Marsh JL (2019) Challenges to orthopaedic resident education. J Am Acad Orthop Surg. 27(12):419-425. https://doi.org/10.5435/JAAOS-D-18-00084

21. Ammar A, Stock AD, Holland R, Gelfand Y, Altschul D (2020) Managing a specialty service during the COVID-19 crisis: lessons from a New York City health system. Acad Med. https://doi.org/10. 1097/ACM.0000000000003440

22. Stambough JB, Curtin BM, Gililland JM, Guild GN 3rd, Kain MS, Karas V, Keeney JA, Plancher KD, Moskal JT (2020) The past, present, and future of orthopedic education: lessons learned from the COVID-19 pandemic. J Arthroplasty. https://doi.org/10.1016/j. arth.2020.04.032

23. Plancher KD, Shanmugam JP, Petterson SC (2020) The changing face of orthopedic education: searching for the new reality after COVID-19. Arthrosc Sports Med Rehabil. https://doi.org/10. 1016/j.asmr.2020.04.007

Publisher's note Springer Nature remains neutral with regard to jurisdictional claims in published maps and institutional affiliations. 